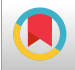

\title{
Sports and Exercise Courses for Medical Students, Time for Propagation
}

\author{
Pardis Noormohammadpour ${ }^{1}$ and Navid Moghadam ${ }^{1,{ }^{*}}$ \\ ${ }^{1}$ Sports Medicine Research Center, Neuroscience Institute, Tehran University of Medical Sciences, Tehran, Iran \\ "Corresponding author: Sports Medicine Research Center, Neuroscience Institute, Tehran University of Medical Sciences, No.7, Al-e Ahmad Highway, Tehran, Iran. Tel: \\ +98-2188630227, Email: navid.mgd@gmail.com \\ Received 2018 October 06; Accepted 2018 October 13.
}

Keywords: Sports Medicine, Medical Education, Iran

The Increase of non-communicable diseases like cardiovascular disease, diabetes, obesity, and the cancers threatens the population's health more than any time before (1) regular physical activity is a preventive factor for most of the non-communicable disease (2). The role of general practitioners in promoting physical activity is undeniable and it highlights the need for equipping future doctors with the knowledge of exercise prescription; not only for healthy people but also for specific groups like diabetic and obese patients. On the other hand, general practitioners are usually responsible for medical care of an evergrowing community of recreational and professional athletes. Their involvement includes but is not limited to preparticipation evaluation, sports injuries, athletes' medical conditions (3), nutrition (4) and doping issues. A Sports and exercise course in medical school can prepare medical students for dealing with these issues during their practice. Considering the current compact curriculum of medical students, it is crucial to design a concise and effective program which is palatable for both school administration and medical students.

An expert panel in Tehran University of Medical Sciences, Tehran, Iran has used the Harden 10 steps method for developing a sports and exercise medicine course for medical students (5). The panel consisted of 6 sports and exercise medicine specialists, a medical education specialist, and a biostatistician. They have developed a 2 weeks elective course based on the American College of Sports Medicine (ACSM)'s 'Guidelines for Exercise Testing and Prescription' and Brukner and Khan's Clinical Sports Medicine which covers exercise prescription and medical issues of athletes. They have shown improvement in the sports and exercise medicine knowledge of medical students after completion of the course. They also asked 4 th, 5 th and 6th year medical students about their priorities in learning about sports and exercise medicine. more than seventy percent of responders regarded exercise prescrip- tion for management of obesity, diabetes and osteoporosis and spinal injuries (6) as their highest priorities of education. It shows the eagerness among medical students for learning about these topics and will justify its inclusion in their programs.

Now we have an example of a course development that has been successful in obtaining its goals of getting medical students familiar with sports and exercise medicine topics. The next step will be a call for adoption of this course in other medical universities in Iran. The addition of sports and exercise medicine in the standard medical education curriculum can prepare general practitioners, frontiers of the health system, in their combat with noncommunicable diseases.

\section{References}

1. Beaglehole R, Bonita R, Horton R, Adams C, Alleyne G, Asaria P, et al. Priority actions for the non-communicable disease crisis. The Lancet. 2011;377(9775):1438-147. doi: 10.1016/s0140-6736(11)60393-0.

2. Briazgounov IP. The role of physical activity in the prevention and treatment of noncommunicable diseases. World Health Stat Q. 1988;41(3-4):242-50. [PubMed: 3232411].

3. Kordi R, Mansournia MA, Nourian RA, Wallace WA. Cauliflower ear and skin infections among wrestlers in Tehran. $J$ Sports Sci Med. 2007;6(CSSI-2):39-44. [PubMed: 24198702]. [PubMed Central: PMC3809051].

4. Kordi R, Abdollahi M, Memari AH, Najafabadi MG. Investigating two different training time frames during Ramadan fasting. Asian J Sports Med. 2011;2(3):205-10. [PubMed: 22375240]. [PubMed Central: PMC3289215].

5. Noormohammadpour P, Halabchi F, Mazaheri R, Mansournia MA, Alizadeh Z, Seif Barghi T, et al. Designing and implementing a curriculum for sports and exercise medicine elective course for undergraduate medical students of Tehran University of Medical Sciences. Br J Sports Med. 2018. doi: 10.1136/bjsports-2018-099462. [PubMed: 29934428].

6. Rostami M, Noormohammadpour P, Sadeghian AH, Mansournia MA, Kordi R. The effect of lumbar support on the ultrasound measurements of trunk muscles: A single-blinded randomized controlled trial. PM R. 2014;6(4):302-8. quiz 308. doi: 10.1016/j.pmrj.2013.09.014. [PubMed: 24107427]. 